\title{
Escherichia coli Alkaline Phosphatase
}

\author{
AN ANALYSIS OF TRANSIENT KINETICS
}

\author{
By S. E. HALFORD* \\ Molecular Enzymology Laboratory, Department of Biochemistry, \\ University of Bristol, Bristol BS8 1TD, U.K.
}

(Received 8 July 1971)

\begin{abstract}
1. The hydrolysis of 2,4-dinitrophenyl phosphate by Escherichia coli alkaline phosphatase at pH5.5 was studied by the stopped-flow technique. The rate of production of 2,4-dinitrophenol was measured both in reactions with substrate in excess of enzyme and in single turnovers with excess of enzyme over substrate. It was found that the step that determined the rate of the transient phase of this reaction was an isomerization of the enzyme occurring before substrate binding. 2. No difference was observed between the reaction after mixing a pre-equilibrium mixture of alkaline phosphatase and inorganic phosphate, with 2,4-dinitrophenyl phosphate at $\mathrm{pH} 5.5$ in the stopped-flow apparatus, and the control reaction in which inorganic phosphate was pre-equilibrated with the substrate. Since dephosphorylation is the rate-limiting step of the complete turnover at pH 5.5, this observation suggests that alkaline phosphatase can bind two different ligands simultaneously, one at each of the active sites on the dimeric enzyme, even though only one site is catalytically active at any given time. 3. Kinetic methods are outlined for the distinction between two pathways of substrate binding, which include an isomerization either of the free enzyme or of the enzyme-substrate complex.
\end{abstract}

The formation of a phosphorylated Escherichia coli alkaline phosphatase led Schwartz (1963) to propose that such a compound was an intermediate in the reaction of this enzyme with phosphate monoesters. Since alkaline phosphatase catalyses the hydrolysis of a wide range of phosphate esters at the same rate, Wilson, Dayan \& Cyr (1964) suggested that dephosphorylation of the enzyme was a common rate-determining step of the overall reaction. Aldridge, Barman \& Gutfreund (1964) found, however, that the dephosphorylation rate was faster

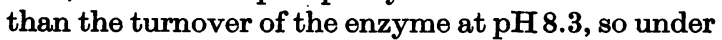
these conditions dephosphorylation could not be rate-determining. By monitoring the hydrolysis of 4-methylumbelliferyl phosphate by alkaline phosphatase in a stopped-flow fluorimeter, Fernley \& Walker (1966) demonstrated that the formation of the phosphoryl-enzyme, concomitant with the liberation of 4-methylumbelliferone, was faster than its decomposition below $\mathrm{pH} 7$, whereas above $\mathrm{pH} 7$, the formation of this intermediate was the ratedetermining step.

Trentham \& Gutfreund (1968) proposed that a kinetically distinct rearrangement of the enzyme or

* Present address: Department of Microbiology, Washington University School of Medicine, St Louis, Mo. 63110, U.S.A. enzyme-substrate complex occurred before chemicel catalysis, since the phosphate esters of 4-nitrophenol and 2,4-dinitrophenol were hydrolysed by $E$. coli alkaline phosphatase at identical rates even when dephosphorylation of the enzyme was not the rate-determining step. This kinetic behaviour is in marked contrast with the non-enzymic hydrolysis of these esters (Kirby \& Varvoglis, 1967). Halford, Bennett, Trentham \& Gutfreund (1969) reported that the binding of the substrate analogue, 2hydroxy-5-nitrobenzyl phosphonate, to alkaline phosphatase in 1.0 M-sodium chloride, $\mathrm{pH} 8.0$, occurred in two reversible steps: enzyme-phosphonate complex-formation followed by a rearrangement of that complex. The value of the rate constant measured from the rate of the enzymephosphonate rearrangement was in excellent agreement with that of the enzyme-substrate rearrangement that had been predicted but could not be directly measured. A rate-limiting conformation change, induced by the phosphate group, provides a mechanism to account for the uniform rates of hydrolysis of a range of phosphate esters.

At pH 8.0, a chromophoric inhibitor was required for the exploration of the mechanism of substrate binding by alkaline phosphatase because the rate-determining step of the overall reaction 
occurred before chemical catalysis. It follows from the lack of a transient phase during substrate hydrolysis at $\mathrm{pH} 8.0$ that no separation of the individual steps of that reaction is possible. At pH 5.5, however, the rapid phase of substrate hydrolysis before the establishment of the steady state indicates that the rate-determining step occurs after the breaking of the phosphate-ester bond. The separation of reaction phases permits direct identification of the intermediates involved in substrate binding. This can be achieved solely by kinetic analysis of the pre-steady-state phase of the reaction. The reactions of alkaline phosphatase with substrates are dependent on solution composition, in particular $\mathrm{pH}$ and ionic strength. All the reactions described in this paper were performed at $\mathrm{pH}$ values close to 5.5 with the dimeric form of the enzyme (Reynolds \& Schlesinger, 1969; S. E. Halford, M. J. Schlesinger \& H. Gutfreund, unpublished work).

\section{MATERIALS AND METHODS}

Assay of alkaline phosphatase. To determine the concentration of alkaline phosphatase solutions, the enzyme was added to a solution of $1.0 \mathrm{~mm}$-4-nitrophenyl phosphate in $1.0 \mathrm{M}$-tris-HCl buffer, $\mathrm{pH} 8.0$ at $25^{\circ} \mathrm{C}$. The rate of release of 4-nitrophenol was measured at $400 \mathrm{~nm}$. Under these conditions, $\epsilon$ of 4-nitrophenol is $1.67 \times$ $10^{4} \mathrm{l} \cdot \mathrm{mol}^{-1} \cdot \mathrm{cm}^{-1}$. A unit of enzyme was defined as the quantity required to liberate $1 \mu \mathrm{mol}$ of 4-nitrophenol/h. The concentration of alkaline phosphatase in solution could then be calculated from the value of $3250 \mathrm{units} / \mathrm{mg}$ for the orystalline enzyme (Malamy \& Horecker, 1964). The molecular weight of the alkaline phosphatase dimer was taken as 86000 (Schlesinger \& Barrett, 1965) and $E_{1 \mathrm{~cm}}^{1 \%}$ at $278 \mathrm{~nm}$ as 7.7 (Rothman \& Byrne, 1963).

Preparation of alkaline phosphatase (EC 3.1.3.1). E. coli C90, which had been grown under phosphate-limiting conditions, were provided by $\mathrm{Dr} \mathrm{K}$. Sargeant (Microbiological Research Establishment, Porton, Wilts., U.K.). The material contained on average $2.5 \mathrm{~g}$ of alkaline phosphatase $/ \mathrm{kg}$ wet wt. of cells. The cells were autolysed by storage on ice for at least 2 weeks before use. Alkaline phosphatase was released into solution by suspending $2 \mathrm{~kg}$ portions of the stored cells in 10 litres of $0.1 \mathrm{M}$-tris-HCl1.0 mM-EDTA, pH8.0. The solid debris was removed by centrifugation. All preparative centrifugations were done with a MSE model 18 machine for at least $30 \mathrm{~min}$ at $15000 \mathrm{~g}$. The supernatant was made $1 \mathrm{~mm}$ in $\mathrm{ZnCl}_{2}$ and then subjected to $\left(\mathrm{NH}_{4}\right)_{2} \mathrm{SO}_{4}$ fractionation. The precipitate from the 50-70\%-satd.- $\left(\mathrm{NH}_{4}\right)_{2} \mathrm{SO}_{4}$ fraction was resuspended in the minimum volume of $0.01 \mathrm{M}$-tris-HCl$1.0 \mathrm{~mm}-\mathrm{ZnCl}_{2}$, $\mathrm{pH} 7.4$, and then dialysed against three changes of $0.01 \mathrm{M}$-tris-HCl buffer, $\mathrm{pH} 7.4$, at $4^{\circ} \mathrm{C}$. After centrifugation to remove material that precipitated during dialysis, the enzyme was adsorbed on a DEAEcellulose column (Whatman DE 32) of bed-height $50 \mathrm{~cm}$ and diameter $8 \mathrm{~cm}$, which had been pre-equilibrated in the same buffer. The column was washed first with $0.01 \mathrm{M}$ tris-HCl-0.05 $\mathrm{M}-\mathrm{NaCl}, \mathrm{pH} \mathrm{7.4,} \mathrm{which} \mathrm{failed} \mathrm{to} \mathrm{eluate} \mathrm{any}$ alkaline phosphatase, and then with $0.01 \mathrm{M}$-tris-HCl-
$0.08 \mathrm{M}-\mathrm{NaCl}, \mathrm{pH} 7.4$, which caused the desorption of the enzyme from the DEAE-cellulose. The elution profile showed a sharp leading edge followed by a broad peak and then a lengthy trailing edge. Fractions from either edge had a lower specific activity than the peak material and were discarded. The specific activity of the peak fractions was $3250 \pm 100$ units/mg and approx. $50 \%$ of the total alkaline phosphatase in the $E$. coli was recovered with this specific activity. The column chromatography was performed at $4^{\circ} \mathrm{C}$.

The peak fractions were made $1 \mathrm{mM}$ in $\mathrm{ZnCl}_{2}$, concentrated by $\left(\mathrm{NH}_{4}\right)_{2} \mathrm{SO}_{4}$ precipitation and stored as an amorphous suspension in $0.1 \mathrm{M}$-tris-HCl $70 \%$-satd. $\left(\mathrm{NH}_{4}\right)_{2} \mathrm{SO}_{4}, \mathrm{pH} \mathrm{8.0}$, at $4^{\circ} \mathrm{C}$. The enzyme was inactivated by storage under these conditions, with a half-life of 6 months. This inactivation was completely reversed by adding a tenfold excess of $\mathrm{ZnCl}_{2}$ to the enzyme solution, even with enzyme that had been stored for over 1 year. Since the addition of zinc to a solution of alkaline phosphatase at $\mathrm{pH}$ values above 8.0 converts the enzyme from the dimeric into the tetrameric form (S. E. Halford, M. J. Schlesinger \& H. Gutfreund, unpublished work), it was necessary to prepare enzyme solutions with maximal specific activity but in the absence of excess of zinc. Hence the procedure described below was used to prepare enzyme solutions from the stock suspension. The suspension was centrifuged, resuspended in the minimum volume of water and dialysed first against $0.1 \mathrm{~mm}-\mathrm{ZnCl}_{2}$, then against water and finally against the requisite buffer solution.

This alkaline phosphatase preparation had the same specific activity as the crystalline enzyme of Malamy \& Horecker (1964). The enzyme was homogeneous with respect to molecular weight both in the analytical ultracentrifuge and on filtration through Sephadex G-200. Samples of the preparation were subjected to electrophoresis for $2 \mathrm{~h}$ at $1 \mathrm{kV}$ on cellulose polyacetate strips (Sephraphore III from Gelman Instrument Co., Ann Arbor, Mich., U.S.A.) in $0.05 \mathrm{~m}$-sodium veronal buffer, pH 8.6. Four protein bands were observed; they all had alkaline phosphatase activity. Electrophoretograms were stained with either Ponceau $S$ in $5 \%(w / v)$ trichloroacetic acid for protein or by the method of Gomori (1951) for enzyme activity. Only one band was observed after electrophoresis of enzyme that had been stored for 8 months, with either the protein or the activity stains.

A freeze-dried sample of alkaline phosphatase from $E$. coli CW 3747 was a gift from $\mathrm{Dr}$ M. J. Schlesinger, Department of Microbiology, Washington University, St Louis, Mo., U.S.A. This enzyme had been prepared by the method of Schlesinger \& Olson (1970).

Substrates and other reagents. Disodium 4-nitrophenyl phosphate tetrahydrate was obtained from Sigma Chemical Co. (St Louis, Mo., U.S.A.) as Sigma 104 phosphatase substrate. The hydrolysis of this ester was monitored at $400 \mathrm{~nm}$ where $\epsilon$ of the 4-nitrophenylate anion is $1.83 \times 10^{4} 1 \cdot \mathrm{mol}^{-1} \cdot \mathrm{cm}^{-1}$. The $\mathrm{pK}$ of 4-nitrophenol is 7.04 and 6.88 in solutions of $I 0.1$ and 1.0 respectively. The mono-2,6-lutidine salt of 2,4-dinitrophenyl phosphate was a gift from Dr A. J. Kirby, University Chemical Laboratory, Cambridge, U.K. (Kirby \& Varvoglis, 1966). Its hydrolysis was measured either at the absorption peak of 2,4-dinitrophenylate, $360 \mathrm{~nm}$, or on the shoulder at $390 \mathrm{~nm}$, where the molar difference extinotion coefficients 
between 2,4-dinitrophenylate and 2,4-dinitrophenyl phosphate are $1.35 \times 10^{4}$ and $1.16 \times 10^{4} 1 \cdot \mathrm{mol}^{-1} \cdot \mathrm{cm}^{-1}$ respectively. The $\mathrm{p} K$ of 2,4-dinitrophenol is 3.76 at an ionic strength of 1.0. All other chemicals were of analytical or reagent grades and were used without further purification.

Tris buffers were adjusted to the requisite $\mathrm{pH}$ with $5 \mathrm{M}-\mathrm{HCl}$ and the final volumes adjusted so that the stated concentration is that of tris. Acetate buffers were prepared in the same manner from sodium acetate and acetio acid. The reported $\mathrm{pH}$ of all solutions is that at room temperature.

Methods. Visible and u.v. spectra, including difference spectra, were recorded with a Perkin-Elmer 402 scanning spectrophotometer. Single extinction measurements were made with a Carl Zeiss PMQ II spectrophotometer. Timecourse absorption measurements were performed in the $1 \mathrm{~cm}$ light-path thermostatistically controlled cuvette of a Beckman DB recording spectrophotometer.

The stopped-flow technique was used as described by Halford et al. (1969).

A $0-100 \%$ transmission scale was established for the stopped-flow apparatus after all the reactants of a system had been mixed except for enzyme. The extinction of the enzyme solution at the wavelength of the experiment was measured separately. The position of the $100 \%$ transmission line was redetermined after completion of the experiment with enzyme. Experimental results were discarded if the drift in the $100 \%$ transmission line was greater than $1 \%$. By this procedure, it was possible to determine accurately the extinction change of a reaction that was completed within the dead time of the stoppedflow apparatus. In biphasic reactions, the slower reaction was extrapolated back to zero time $(3 \mathrm{~ms}$ before flow stopped) so that the necessary corrections could be made in the analysis of both the rate and the amplitude of the faster phase. Alternatively, the method of Guggenheim (1926) was used to evaluate the individual rate constants from biphasic records.

\section{RESULTS}

Reactions with excess of substrate. The hydrolysis of excess of 2,4-dinitrophenyl phosphate by the $E$. coli alkaline phosphatase dimer was studied by the stopped-flow technique. Fig. 1 is the record of the transmission change at $390 \mathrm{~nm}$ after mixing in the stopped-flow apparatus $10 \mu \mathrm{M}$-alkaline phosphatase in $0.01 \mathrm{M}$-tris-HCl-0.10 M-sodium chloride, pH 8.0, with $0.10 \mathrm{~mm}$-2,4-dinitrophenyl phosphate in $0.10 \mathrm{M}$-sodium acetate buffer, pH 5.5. The final $\mathrm{pH}$ of the reaction mixture was 5.65. As a routine, it was preferable to mix enzyme weakly buffered at an alkaline $\mathrm{pH}$ with a strongly buffered solution of the substrate at the required acidic $\mathrm{pH}$ value. The incubation of alkaline phosphatase at pH5.5 led to its partial inactivation in the absence, but not in the presence, of substrate and this inactivation was enhanced by increasing the ionic strength (cf. Pigretti \& Milstein, 1965). However, no facet of the reaction between enzyme and substrate at acidic $\mathrm{pH}$ values was found to be caused by the
$\mathrm{pH}$ jump on mixing enzyme at $\mathrm{pH} 8.0$ with substrate at pH 5.5. In every case, qualitatively identical results were obtained when the enzyme solution was prepared at $\mathrm{pH} 5.5$ and then mixed with substrate at the same $\mathrm{pH}$ value.

The observed reaction record in Fig. 1 reveals a biphasic production of 2,4-dinitrophenol, i.e. a transient phase followed by the steady state. The steady-state hydrolysis of 2,4-dinitrophenyl phosphate proceeds at a rate of about $0.5 \mathrm{~mol}$ of substrate/s per mol of enzyme under these experimental conditions. The observed approach to the steady state can be described by a single exponential equation. The first-order rate constant from this process is $14 \mathrm{~s}^{-1}$ under the conditions used for this experiment. The amplitude of transient product formation in Fig. 1 was measured after extrapolating both the steady-state and the transient phases back to zero time: the extinction difference was 0.056 , equivalent to a 2,4-dinitrophenol concentration of 4.8 $\mu \mathrm{M}$. The enzyme concentration in the reaction was $5.0 \mu \mathrm{M}$. At this enzyme concentration, no alterations were observed in either the rate or the amplitude of transient product formation or in the steady-state rate when the reaction was studied at different substrate concentrations in the range $25 \mu \mathrm{M}-0.50 \mathrm{mM}$.

The hydrolysis of 2,4-dinitrophenyl phosphate by alkaline phosphatase at $\mathrm{pH} 5.65$ was also studied when both enzyme and substrate solutions contained 1.0 M-sodium chloride. The reaction proceeded in a manner qualitatively similar to that described above, but transient product formation was faster $\left(k_{\text {obs. }}=33 \mathrm{~s}^{-1}\right)$. The amount of product released in the transient phase was again equal to the enzyme concentration.

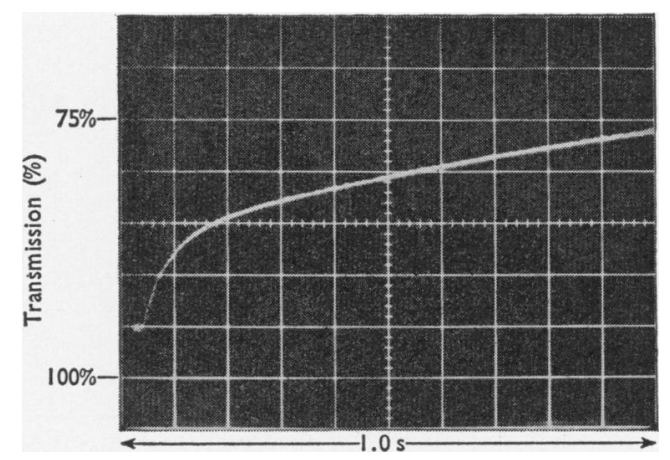

Fig. 1. Spectrophotometric record at $390 \mathrm{~nm}$ of a stoppedflow observation after mixing $10 \mu \mathrm{M}$-alkaline phosphatase in $0.01 \mathrm{~m}$-tris-HCl-0.10 $\mathrm{m}-\mathrm{NaCl}, \mathrm{pH} 8.0$, with $0.10 \mathrm{~mm}$ 2,4-dinitrophenyl phosphate in $0.10 \mathrm{M}$-sodium acetate, pH 5.5. Two reaction traces are superimposed.

Bioch. 1971, 125 
Experiments were performed to examine the effect of $P_{1}$ on this reaction under the conditions used for Fig. 1. Identical records were obtained from the reactions when either $10 \mu \mathrm{M}$-alkaline phosphatase was mixed with a solution of $0.10 \mathrm{~mm}-2,4$ dinitrophenyl phosphate and $1.0 \mathrm{~mm} \cdot \mathrm{P}_{1}$ at $\mathrm{pH} 5.5$ or if the $P_{1}$ was pre-equilibrated with the enzyme solution. This was found when the enzyme solution (in either the absence or presence of $P_{1}$ ) was prepared at $\mathrm{pH} 8.0$ or 5.5. In these pairs of experiments, the reaction profile was qualitatively similar to that in the absence of $P_{1}$ : transient 2,4-dinitrophenol production was observed before the steady state (cf. Fig. 1). The addition of $P_{1}$ caused no change to the amplitude of transient product formation but decreased the rate constant of the transient phase from 14 to $3.6 \mathrm{~s}^{-1}$.

Further inspection of Fig. 1 revealed that some 2,4-dinitrophenyl phosphate was hydrolysed in an instant phase completed within the dead-time of the stopped-flow apparatus, for there was an extinction difference between the $100 \%$ transmission point and the start of the observed transient phase extrapolated back to zero time. The amplitude of this instant phase was not found to be reproducible with different preparations of the enzyme, the extent of this variation being equivalent to 2,4-dinitrophenol concentrations from 0 to $66 \%$ of the enzyme concentration. This is in contrast with the amplitude of the observed transient, which was found to be very reproducible with different enzyme preparations, even with samples that also displayed an instant phase. No instant phase was observed with the alkaline phosphatase from $E$. coli CW 3747. In all other respects the reactions of alkaline phosphatase from $E$. coli strains $\mathrm{C} 90$ and CW 3747 were found to be identical. Further, no differences have been detected between the amino acid compositions of the enzymes from the two sources (M. J. Schlesinger, personal communication). This instant phase of substrate hydrolysis is therefore considered to be an artifact generated by different methods of enzyme preparation. The large scale of the enzyme preparation in this paper necessitated the use of ammonium sulphate, an isolation procedure not used by Schlesinger \& Olson (1970).

Reactions with excess of enzyme. The hydrolysis of 2,4-dinitrophenyl phosphate by alkaline phosphatase at pH 5.65 was further studied by examining this reaction at a fixed enzyme concentration but with varied substrate concentrations from above to below that of the enzyme. Spectrophotometric records of single turnovers of alkaline phosphatase are shown in Fig. 2. In these reactions, the stopped-flow technique was employed to mix enzyme in $0.01 \mathrm{M}$-tris- $\mathrm{HCl}-0.00 \mathrm{M}$-sodium chloride, $\mathrm{pH} 8.0$, with substrate in $0.10 \mathrm{M}$-sodium acetate, pH5.5. Under these conditions, it was found that the complete hydrolysis of 2,4dinitrophenyl phosphate by excess of alkaline phosphatase was a monophasic reaction that could be described by a single first-order rate constant. This behaviour was observed for single turnovers at all the concentrations of reactants used in these experiments. But it is noteworthy that the observed rate constant from the reactions in Fig. 2 is larger at the lower substrate concentration. The same results were obtained when the enzyme solution was prepared at $\mathrm{pH} 5.5$ and similar observations were also made when the experiment was repeated at a higher ionic strength with both solutions containing $1.0 \mathrm{M}$-sodium chloride.

The rate constant $\left(k_{\text {obs. }}\right)$ describing the production of 2,4-dinitrophenol in a single turnover of alkaline phosphatase (or the rate constant from the transient formation of 2,4-dinitrophenol when substrate

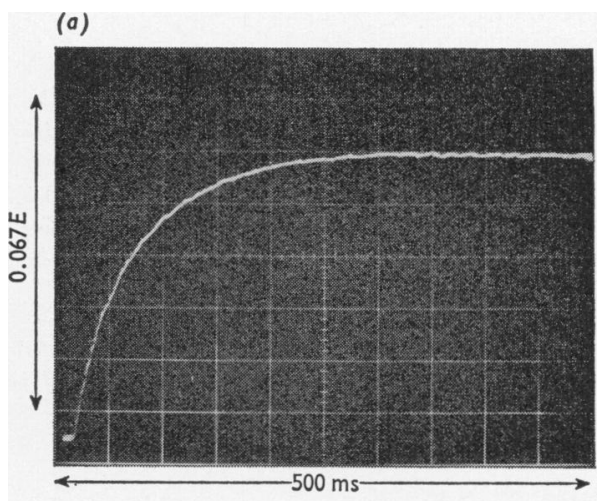

(b)

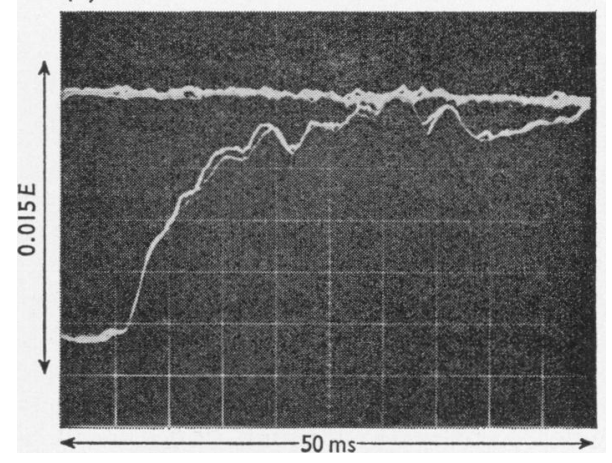

Fig. 2. Spectrophotometric records at $390 \mathrm{~nm}$ of stoppedflow observations after mixing $12.6 \mu \mathrm{M}$-alkaline phosphatase in $0.01 \mathrm{~m}$-tris-HCl-0.10 $\mathrm{M}-\mathrm{NaCl}, \mathrm{pH} 8.0$, with 2,4dinitrophenyl phosphate $(a, 5.3 \mu \mathrm{M} ; b, 1.6 \mu \mathrm{M})$ in $0.10 \mathrm{M}$ sodium acetate, $\mathrm{pH}$ 5.5. Two reaction traces are superimposed. The horizontal trace (displaying the final extinction of the reaction mixture) was recorded about $30 \mathrm{~s}$ after completion of the second reaction trace. 


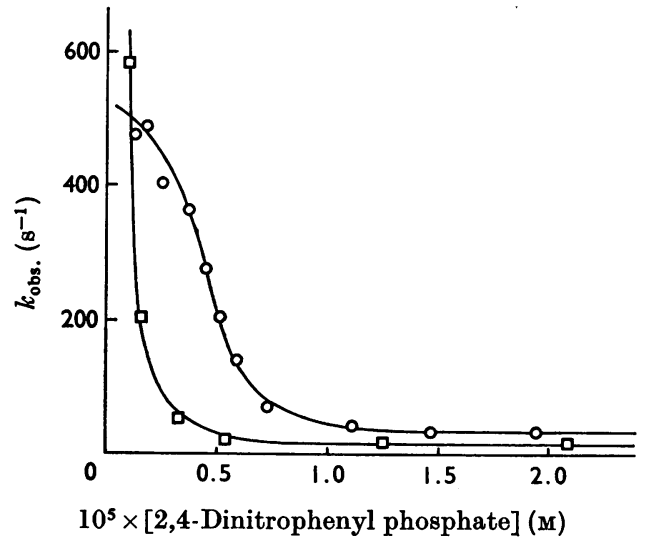

Fig. 3. Relationships between the observed rate constants $\left(k_{\text {obs. }}\right)$ from either total 2,4-dinitrophenyl phosphate hydrolysis (when enzyme is in excess of substrate) or transient 2,4-dinitrophenol production (when substrate is in excess of enzyme) and the substrate concentration in the reaction mixture. $\square$, Observed rate constants with $6.3 \mu \mathrm{M}$-alkaline phosphatase at $\mathrm{pH} 5.65$, $I, 0.1$ (cf. Fig. 2); O, observed rate constants with $9.5 \mu \mathrm{M}$ alkaline phosphatase at $\mathrm{pH} 5.65, I, 1.1$. Enzyme concentrations refer to those in the reaction mixture.

is in excess of enzyme) is shown as a function of the substrate concentration in Fig. 3. Fig. 3 shows results from two experiments at $\mathrm{pH} 5.65$, at ionic strengths of either 0.1 or 1.1. Substrate concentrations were determined from the observed extinction change on the complete hydrolysis of substrate in these reactions.

\section{DISCUSSION}

The reactions of dimeric alkaline phosphatase with excess of substrates at acidic $\mathrm{pH}$ values have been studied by Fernley \& Walker (1966, 1968), Ko \& Kezdy (1967) and Trentham \& Gutfreund (1968). The observations on this reaction presented here confirm their findings, but an alternative interpretation is developed from them. The biphasic release of product (Fig. 1) is compatible with the mechanism proposed by Wilson et al. (1964) provided $k_{2} \gg k_{3}$ :

$$
\begin{aligned}
& \mathrm{E}+\operatorname{ROP} \underset{k_{-1}}{\stackrel{k_{+1}}{\rightleftharpoons}} \mathrm{E} \cdot \operatorname{ROP} \stackrel{k_{2}}{\longrightarrow} \\
& \mathrm{E} \cdot \mathrm{P}_{\mathrm{i}} \stackrel{k_{3}}{\longrightarrow} \mathrm{E}+\mathrm{P}_{\mathrm{i}} \\
& + \\
& \mathrm{ROH}
\end{aligned}
$$

where $\mathrm{ROH}$ is the alcohol released on hydrolysis of the ester ROP; E.ROP and E.P $P_{i}$ are enzymesubstrate and -orthophosphate complexes. This scheme has already been shown to be an insufficient description of the catalytic mechanism of alkaline phosphatase at pH8.0 (Trentham \& Gutfreund, 1968; Halford et al. 1969). However, with this mechanism, the exponential approach to the steady state $\left(k_{\text {obs. }}\right)$ is given by:

$$
k_{\text {obs. }}=k_{2}+k_{3}
$$

and the catalytic-centre activity $\left(k_{\text {cat. }}\right)$ by

$$
k_{\text {cat. }}=\left(k_{2} \times k_{3}\right) /\left(k_{2}+k_{3}\right)
$$

at saturating substrate concentrations (Gutfreund \& Sturtevant, 1956). Under conditions when $k_{2} \gg k_{3}$, as in the present investigation, $k_{\text {obs. }}=k_{2}$ and $k_{\text {cat. }}=k_{3}$. At saturating substrate concentration and $k_{2} \gg k_{3}$, the product released in the transient phase is a direct measure of the concentration of enzyme active sites (Gutfreund, 1965).

The previous observation that $1 \mathrm{~mol}$ of alcohol is released $/ \mathrm{mol}$ of enzyme in the transient phase of this reaction has been confirmed. The molarities of enzyme solutions are quoted for the dimeric form of alkaline phosphatase, which is the sole aggregation species present in these experiments (S. E. Halford, M. J. Schlesinger \& H. Gutfreund, unpublished work). The two subunits of the alkaline phosphatase dimer are synthesized from the same cistron (Garen \& Garen, 1963) and appear to be chemically identical (Rothman \& Byrne, 1963). This stoicheiometry of transient product formation cannot be due to enzyme impurity. Nor can it be a consequence of the isoenzymic heterogeneity of alkaline phosphatase: the same stoicheiometry was observed with enzyme featuring either one or four electrophoretically distinct bands. Fife (1967) examined the amplitude of this transient phase by back extrapolation of the steady state to zero time and measured the release of more than $1 \mathrm{~mol}$ of product/mol of enzyme. The difference between this result and the amplitude of transient product formation measured after direct observation by the stopped-flow technique might be due to the existence of the non-reproducible phase of substrate hydrolysis completed within the dead-time of the stoppedflow apparatus.

The transient phase of substrate hydrolysis by alkaline phosphatase was studied in the presence of the competitive inhibitor $P_{i}$. The decrease in the rate constant of transient product formation, without alteration to its amplitude, is the expected effect of a competitive inhibitor on this reaction provided that the enzyme-inhibitor complex is in rapid equilibrium with free enzyme and inhibitor (Ko \& Kézdy, 1967). But the existence of the transient phase during substrate hydrolysis indicates that dephosphorylation limits the catalytic-centre activity at acidic $\mathrm{pH}$ values (Trentham \& Gutfreund, 1968) presenting further identification of this process as the rate-determining step under acidic 
conditions. Identical results were obtained in this reaction when $P_{1}$ was preincubated with either substrate or enzyme, and also when the enzyme- $\mathbf{P}_{\mathbf{1}}$ mixture was prepared at either pH 8.0 or 5.5.

Incubation of alkaline phosphatase with $\mathbf{P}_{\mathbf{1}}$ causes the formation of an enzyme-phosphate complex at $\mathrm{pH} 8.0$ and a covalently incorporated phosphoryl-enzyme at pH5.5 (Reid, Pavlic, Sullivan \& Wilson, 1969). Under these conditions, the stoicheiometry of both these compounds is $1 \mathrm{~mol}$ of $P_{1} / \mathrm{mol}$ of enzyme dimer (Applebury, Johnson \& Coleman, 1970). Phosphorylation of the enzyme occurs at the active site since only one specific serine residue can be phosphorylated by either $\mathrm{P}_{1}$ or glucose 6-phosphate at low $\mathrm{pH}$ values (Schwartz, 1963). Thus it might have been expected that on mixing phosphoryl-alkaline phosphatase with 2,4-dinitrophenyl phosphate in the stopped-flow apparatus, substrate hydrolysis would not occur until $P_{1}$ had dissociated from the enzyme. If this were the case, the reaction record would display a linear trace of the steady-state production of 2,4-dinitrophenol proceeding from $100 \%$ transmission at zero time. But preincubation of the enzyme with $\mathrm{P}_{1}$ did not abolish transient product formation.

Even though only one active site on the alkaline phosphatase dimer functions in catalysis at any given time and only one site is readily saturated with $\mathbf{P}_{1}$, the enzyme is catalytically effective while a competitive inhibitor remains associated with it. Therefore, despite the fact that studies with either substrate or inhibitor alone reveal only one active site, the alkaline phosphatase dimer must contain two potentially active sites and the association of ligand with the active site of one subunit does not necessarily prevent the active site on the other subunit from being able to bind a different ligand, albeit with a modified dissociation constant.

It has been demonstrated (Trentham \& Gutfreund, 1968) that the observed rate constant $\left(k_{\text {obs. }}\right)$ from the transient phase of substrate hydrolysis at this $\mathrm{pH}$ value can be directly equated to $k_{2}$, the rate constant for the bond-breaking step in the mechanism of Wilson et al. (1964). Thus $k_{2}$ is evaluated as $14 \mathrm{~s}^{-1}$ from the hydrolysis of 2,4dinitrophenyl phosphate (Fig. 1). It is noteworthy that Fernley \& Walker (1969) obtained a very similar value for $k_{2}$ from the transient during hydrolysis of 4-methylumbelliferyl phosphate under comparable conditions. Trentham \& Gutfreund (1968) had noted that the steady-state hydrolysis of the phosphate esters of 2,4-dinitrophenol and 4-nitrophenol proceeded at identical rates even when $k_{2}$ is rate-limiting, and had consequently suggested that some additional step in the enzyme mechanism determined the rate of transfer of the phosphate group from the substrate to the enzyme.
Since a parallel observation has now been made after direct examination of transient product formation, the same conclusion must also apply here. The rate of this additional step must be invariant for different substrates.

The extension of these studies on 2,4-dinitrophenyl phosphate hydrolysis by alkaline phosphatase at acidic $\mathrm{pH}$ values to the situation when enzyme was in excess of substrate was performed to identify the nature of this additional step. Figs. 2 and 3 show that faster first-order rate constants were obtained from the total hydrolysis of 2,4dinitrophenyl phosphate by excess of alkaline phosphatase at lower initial substrate concentrations. Kinetic equations were derived for the mechanisms of substrate binding given below, in an attempt to relate this concentration dependence of $k_{\text {obs. }}$ to a particular mechanism:

$$
\begin{aligned}
& \mathrm{E}^{*}+\mathrm{S} \underset{k_{-1}^{*}}{\stackrel{k_{+1}^{*}}{\rightleftharpoons}} \mathrm{E} * \mathrm{~S} \\
& \mathrm{E}+\mathrm{S} \underset{k_{-1}}{\stackrel{k_{+1}}{\rightleftharpoons}} \mathrm{ES} \stackrel{k_{+2}}{\underset{k_{-2}}{\rightleftharpoons}} \mathrm{E} * \mathrm{~S} \\
& \mathrm{E} \underset{k_{0}}{\stackrel{k_{0}^{*}}{\rightleftharpoons}} \mathrm{E}^{*} ; \mathrm{E}^{*}+\mathrm{S} \underset{k_{-1}^{*}}{\stackrel{k_{+1}^{*}}{\rightleftharpoons}} \mathrm{E} * \mathrm{~S}
\end{aligned}
$$

Given that the bond-breaking step plays no part in determining the rate of liberation of the alcohol, the transfer of phosphate from substrate to enzyme will be concomitant with the formation of $E^{*} S$, the intermediate in which rapid chemical catalysis occurs. Hence analysis of the kinetics of 2,4dinitrophenol liberation need only consider the rate of formation of the $E^{*} S$ intermediate at different reactant concentrations. In the analysis of both two-step mechanisms ( 2 and 3 ), it will be assumed that the bimolecular binding step is much faster than the unimolecular isomerization. Linear equations can only be derived for the transient kinetics of non-equilibrium systems when the concentration of one of the reactants is invariant over the time-course of the reaction. But by deriving two equations, one for each of the situations in which one reactant is in large excess over the other, it is possible to deduce the variation of $k_{\text {obs. }}$ over the complete range of reactant concentrations.

For mechanism (1):

$$
k_{\mathrm{obs} .}=k_{-1}^{*}+k_{+1}^{*}\left(\left[\mathrm{E}^{*}\right]+[\mathrm{S}]\right)
$$

where $\left[\mathbf{E}^{*}\right]$ and $[\mathrm{S}]$ are the concentrations of free enzyme and substrate. Thus mechanism (1) demands a linear relationship between the sum of the reactant concentrations and $k_{\text {obs. }}$. It is unable to accommodate the experimental observations. Vallee \& Williams (1968) proposed that metalloenzymes such as the $E$. coli alkaline phosphatase 
dimer were poised ready for catalytic activity in the absence of substrate. This proposal is incompatible with Fig. 3.

For mechanism (2), when $[\mathrm{E}] \gg[\mathrm{S}]$,

$$
k_{\text {obs. }}=k_{-2}+\frac{k_{+2}}{1+\frac{K_{1}}{[\mathrm{E}]}}
$$

and when $[\mathbf{E}] \ll[S]$

$$
k_{\mathrm{obs} .}=k_{-2}+\frac{k_{+2}}{1+\frac{K_{1}}{[\mathrm{~S}]}}
$$

$K_{1}$ is defined as $k_{-1} / k_{+1}$. On the basis of this scheme, a minimum value of $k_{\text {obs. }}$ should be observed when $([\mathrm{E}]+[\mathrm{S}])$ is at a minimum. If $K_{1}$ is small, this will occur at the equivalence point of $[\mathrm{E}]=[\mathrm{S}]$. An increment in the concentration of either enzyme or substrate from the equivalence point should lead to an increase in $k_{\text {obs. }}$, and at very high concentrations of enzyme or substrate, plateau regions are expected where $k_{\text {obs. }}$ invariantly equals $\left(k_{-2}+k_{+2}\right)$. Although Fig. 3 exhibits an increase in $k_{\text {obs. }}$ as the free enzyme concentration was increased (by decreasing the substrate concentration), the complementary increase in $k_{\text {obs. }}$ when substrate was in excess of enzyme was not observed. Hence a conformation change subsequent to ligand binding is not the mechanism that accounts for the uniform rates of transient product formation under these conditions.

The formation of $\mathrm{E} * \mathrm{~S}$ will occur in two phases with mechanism (3). First, substrate will associate with the $\mathrm{E}^{*}$ conformation of the enzyme in a rapid bimolecular step. Secondly, the enzyme will undergo the isornerization from the $\mathrm{E}$ to the $\mathrm{E}^{*}$ state to permit the binding of further ligand. Provided $[\mathrm{S}] \gg\left([\mathrm{E}]+\left[\mathrm{E}^{*}\right]\right)$, the observed rate constant for the second phase is given by

$$
k_{\text {obs. }}=k_{0}^{*}+\frac{k_{0}}{1+\frac{[\mathrm{S}]}{K_{1}^{*}}}
$$

$K_{1}^{*}$ is defined as $k_{-1}^{*} / k_{+1}^{*}$. When $[\mathrm{S}] \gg K_{1}^{*}$, the above equation reduces to $k_{\text {obs. }}=k_{0}^{*}$. It can also be shown that when $[\mathrm{E}] \gg[\mathrm{S}] \gg\left[\mathrm{E}^{*}\right], k_{\text {obs. }}=k_{0}^{*}+k_{0}$. (The concentration of the $\mathrm{E}^{*}$ species must always be smaller than that of the substrate in order to observe the E-to-E* isomerization of this scheme.) Mechanism (3) demands that the value of $k_{\text {obs. }}$ should decrease from $\left(k_{0}^{*}+k_{0}\right)$ to $\left(k_{0}^{*}\right)$ as the initial substrate concentration is increased from $[\mathrm{S}]<[\mathrm{E}]$ to $[\mathrm{S}]>[\mathrm{E}]$. This qualitative concentration dependence fits Fig. 3. The $K_{m}$ for 2,4-dinitrophenyl phosphate at pH 5.5 is too small $\left(K_{m} \ll 1 \mu \mathrm{M}\right)$ to be determined and in the present experiments the condition $\left[\mathrm{E}_{0}\right]>K_{m}$ is also fulfilled.

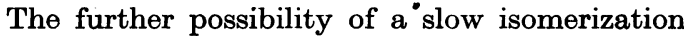
between unreactive and reactive forms of the substrate before association with the enzyme can be dismissed, for such a pathway predicts a decrease in the amplitude of the observed transient on increasing the substrate concentration. At high substrate concentrations, transient product formation would be subdivided into two phases; a rapid phase as enzyme and reactive substrate combine and then a slower transient the rate of which would be determined by the substrate isomerization. This has not yet been observed with alkaline phosphatase, although related behaviour has been described for the substrates of some other enzymes (Trentham, McMurray \& Pogson, 1969).

It is therefore concluded that the catalytic mechanism of alkaline phosphatase at pH5.65 involves an isomerization of the enzyme before substrate binding. Qualitatively, the mechanism is the same at ionic strengths of 0.1 and 1.1. From the asymptote values of $k_{\text {obs. }}$ at high and low substrate concentrations, $k_{0}^{*}$ is evaluated as $33 \mathrm{~s}^{-1}$ and $k_{0}$ as about $500 \mathrm{~s}^{-1}$ at an ionic strength of 1.1 , which gives a $k_{0} / k_{0}^{*}$ ratio of 15 . The ratio of $k_{0} / k_{0}^{*}$ is even larger at the lower ionic strength, where $k_{0}$ was too fast to measure. Extension of these studies to still lower substrate concentrations is impracticable because further decreases cause the reaction rate to become immeasurably fast and the reaction amplitude to become immeasurably small. Consideration of mechanism (3) shows that the substrate concentration at the point where $k_{\text {obs. }}=\left(k_{0}^{*}+k_{0}\right) / 2$ is related to $K_{1}^{*}$. An examination of Fig. 3 reveals that $K_{1}^{*}$ is larger at an ionic strength of 1.1 than it is at 0.1 .

From the values of the $k_{0} / k_{0}^{*}$ ratios, alkaline phosphatase at pH5.65 is present almost completely in the unreactive $E$ state in the absence of ligand. On addition of excess of substrate, the E-to-E* equilibrium is displaced towards $\mathbf{E}^{*}$ (at the rate of $k_{0}^{*}$ ) by the formation of $E^{*} S$. This isomerization determines the rate of the transient observed in Fig. 1. Subsequently, dephosphorylation of the enzyme- $\mathbf{P}_{\mathbf{i}}$ intermediate limits the steady state under these conditions, for only this rate is enhanced by the presence of alternative $P_{i}$ acceptors (Trentham \& Gutfreund, 1968). If a conformation change determines the overall rate of an enzyme-catalysed reaction, then the absence of 'hysteresis' (Frieden, 1970) during the reaction indicates that a second conformation change returns the enzyme to its original state at some point in the turnover. But in the case under discussion, the conformation change only controls the rate of transient product formation. Thus, under these conditions, it is not possible to determine if the complete turnover involves a second conformation change that returns the enzyme from $E^{*}$ back 
to the $\mathrm{E}$ state. Without this information, it is impossible to establish a mechanism for the competitive inhibition of substrate hydrolysis by $\mathbf{P}_{\mathbf{1}}$, even though both ligands can be bound to the enzyme at the same time. Consequently the observations about the simultaneous association of substrate and $\mathbf{P}_{\mathbf{i}}$ with the alkaline phosphatase dimer at acidic $\mathrm{pH}$ values cannot be discussed further at the present time. However, it remains an open question whether the phosphoryl-enzyme isolated after incubation with $\mathrm{P}_{\mathrm{i}}$ at low $\mathrm{pH}$ values is identical with the enzyme-phosphate intermediate of the catalytic mechanism.

Reid \& Wilson (1971) have proposed that the steady-state rate of substrate hydrolysis by alkaline phosphatase is determined at all $\mathrm{pH}$ values by a conformation change between two isomers of the free enzyme, one of which can bind substrate and the other $\mathbf{P}_{1}$. They suggested that the decrease in the amplitude of transient product formation caused by $\mathrm{pH}$ increases was due to a change in the position of the pre-equilibrium between the two isomers, which favoured the substrate-binding form at low $\mathrm{pH}$ values and the phosphate-binding form at high $\mathrm{pH}$ values. Two experimental observations reported here are irreconcilable with the scheme of Reid \& Wilson (1971): first, the identical rates of transient product formation with different substrates because the transient rate is determined by the bond-breaking step in their mechanism; secondly, the unaltered amplitude of this transient phase after preincubation of the enzyme with $P_{i}$. In experiments performed at constant $I$, Trentham \& Gutfreund (1968) found that the presence of tris enhanced the catalytic-centre activity of alkaline phosphatase to a much greater extent at pH5.90 than at $\mathrm{pH}$ 8.11, and concluded that this activation was caused by the effect of the alternative phosphate acceptor on the dephosphorylation rate, which determines the catalytic-centre activity only at acidic $\mathrm{pH}$ values. The tris activation of the catalytic-centre activity at $\mathrm{pH}$ 8.0 discussed by Reid \& Wilson (1971) is probably an ionic-strength effect, for a similar activation is produced by sodium chloride at alkaline $\mathrm{pH}$ values (Wilson et al. 1964; Fernley \& Walker, 1968). Reid \& Wilson (1971) also suggest that the binding of 2-hydroxy-5nitrobenzyl phosphonate to alkaline phosphatase at pH 8 and $I$ of 1 can be accommodated by mechanism 3 (where $S$ would represent the inhibitor). However, this cannot be the case, since the observed reciprocal relaxation time $(1 / \tau)$ for the mechanism proposed by Halford et al. (1969) (i.e. mechanism 2) is :

$$
\frac{1}{\tau}=k_{-2}+\frac{k_{+2}}{1+\frac{K_{1}}{[\mathrm{E}]+[\mathrm{S}]}}
$$

and that for Reid \& Wilson's (1971) suggestion (mechanism 3) is :

$$
\frac{1}{\tau}=k_{0}^{*}+\frac{k_{0}}{1+\frac{[\mathrm{S}]}{K_{1}^{*}+\left[\mathrm{E}^{*}\right]}}
$$

Only the former mechanism is consistent with the results of Halford et al. (1969).

The experimental results at $\mathrm{pH} 5.5$ and 8.0 clearly demonstrate the use of kinetic methods to describe alternate mechanisms of substrate binding under different conditions.

The observation that the rate of enzymic hydrolysis of a family of esters is independent of the $\mathrm{p} K_{\mathrm{a}}$ of the leaving group only shows that the bondbreaking step is not rate-limiting (Gutfreund, 1968; Jencks, 1969). In this case, the identification of a unimolecular step before the bimolecular process of ligand binding is strong evidence for the existence of a conformation change in the protein. This conformation change determines the rate of transient product formation. But the amplitude of the transient phase corresponds to $1 \mathrm{~mol}$ of product $/ \mathrm{mol}$ of dimeric enzyme. It is possible that this stoicheiometric limitation is caused by the necessary conformation change occurring in only one subunit of the dimeric enzyme at a time.

I thank Dr H. Gutfreund and Dr D. R. Trentham for extensive discussion and advice, and $\mathrm{Dr} K$. Sargeant and Mr A. R. Whitaker for growing the $E$. coli. This research was financed by grants from the Science Research Council.

\section{REFERENCES}

Aldridge, W. N., Barman, T. E. \& Gutfreund, H. (1964). Biochem.J. 92, $23 \mathrm{c}$.

Applebury, M. L., Johnson, B. P. \& Coleman, J. E. (1970). J. biol. Chem. 245, 4968.

Fernley, H. N. \& Walker, P. G. (1966). Nature, Lond., 212, 1435.

Fernley, H. N. \& Walker, P. G. (1968). Biochem. J. 110, $11 \mathrm{P}$.

Fernley, H. N. \& Walker, P. G. (1969). Biochem. J. 111, 187.

Fife, W. K. (1967). Biochem. biophys. Res. Commun. 28, 309.

Frieden, C. (1970). J. biol. Chem. 245, 5788.

Garen, A. \& Garen, S. (1963). J. molec. Biol. 7, 13.

Gomori, G. (1951). J. Lab. clin. Med. 37, 526.

Guggenheim, E. A. (1926). Phil. Mag. 2, 538.

Gutfreund, H. (1965). An Introduction to the Study of Enzymes, p. 61. Oxford: Blackwell Scientific Publications.

Gutfreund, H. (1968). Biochem. J. 110, 2 P.

Gutfreund, H. \& Sturtevant, J. M. (1956). Biochem. J. $63,656$.

Halford, S. E., Bennett, N. G., Trentham, D. R. \& Gutfreund, H. (1969). Biochem. J. 114, 243.

Jencks, W. P. (1969). Catalysis in Chemistry and Enzymology, p. 51. New York: McGraw-Hill. 
Kirby, A. J. \& Varvoglis, A. G. (1966). J. Am. chem. Soc. 88, 1823.

Kirby, A. J. \& Varvoglis, A. G. (1967). J. Am. chem. Soc. $89,415$.

Ko, S. H. D. \& Kézdy, F. J. (1967). J. Am. chem. Soc. 89, 7139 .

Malamy, M. H. \& Horecker, B. L. (1964). Biochemistry, Easton, 3, 1893.

Pigretti, M. M. \& Milstein, C. (1965). Biochem.J. 94, 106.

Reid, T. W., Pavlic, M., Sullivan, D. J. \& Wilson, I. B. (1969). Biochemistry, Easton, 8, 3184.

Reid, T. W. \& Wilson, I. B. (1971). Biochemistry, Easton, $10,380$.

Reynolds, J. A. \& Schlesinger, M. J. (1969). Biochemistry, Easton, 8, 4278.
Rothman, F. \& Byrne, R. (1963). J. molec. Biol. 6, 330.

Schlesinger, M. J. \& Barrett, K. (1965). J. biol. Chem. 240, 4284.

Schlesinger, M. J. \& Olson, R. (1970). Analyt. Biochem. 36, 86.

Schwartz, J. H. (1963). Proc. natn. Acad. Sci. U.S.A.49, 871.

Trentham, D. R. \& Gutfreund, H. (1968). Biochem. J. 106, 455.

Trentham, D. R., McMurray, C. H. \& Pogson, C. I. (1969). Biochem. J. 114, 19.

Vallee, B. L. \& Williams, R. J. P. (1968). Proc.natn. Acad. Sci. U.S.A. 59, 498.

Wilson, I. B., Dayan, J. \& Cyr, K. (1964). J. bioi. Chem. 239, 3184. 